\title{
PTSD prevalence among resident mothers and their offspring in Rwanda 25 years after the 1994 genocide against the Tutsi
}

Celestin Mutuyimana ${ }^{1,2^{*}}$ (D), Vincent Sezibera ${ }^{1}$, Epaphrodite Nsabimana ${ }^{2}$, Lambert Mugabo $^{1}$, Cindi Cassady ${ }^{3}$, Clarisse Musanabaganwa ${ }^{4}$ and Yvonne Kayiteshonga ${ }^{5}$

\begin{abstract}
Background: The 1994 Genocide against the Tutsi was a major traumatic event affecting nearly all Rwandans. Significant psychological sequels continue to occur in the population 25 years after, with a high prevalence of posttraumatic stress disorder (PTSD) found in women. Three groups are typically designated with regard to the Genocide against the Tutsi: those who were targeted and categorized as genocide "survivors," those who were in the country during the genocide and were the "non-targeted" group, and those who were outside of the country, referred to as the "1959 returnees." Each group experienced various traumatic events during and in the aftermath of the genocide. Offspring of the designated groups, currently exhibit symptoms of PTSD disregarding of being born in the years following the genocide. A number of studies have described the prevalence of PTSD in the general adult population. There is a lack of research comparing the prevalence of PTSD in women and their offspring among these three target groups, therefore, this study aimed to bridge the gap.

Methods: We conducted a comparative cross-sectional study with a sample of 432 mothers and 432 children in three categories: genocide survivors, in country non-targeted and 1959 returnees. Participant ages for children were between 14 to 22 years and for mothers, between the ages of 32 to 87 years. The UCLA-PTSD DSM-5, PTSD Check list-5 and Life events Checklist- 5 were translated from English to Kinyarwanda and were used to assess exposure to trauma and the prevalence of PTSD symptoms in Rwandan mothers and their offspring.

Results: Key Results yield a PTSD rate of 18.8, 6.2, 5.2\% within survivors, in country non-targeted, and returnees respectively with an average PTSD rate of $43.8 \%$ for parents, and $16.5 \%$ for offspring.

Conclusion: PTSD among the mothers' groups and their offspring have been found, specifically in the offspring of genocide survivors. Considering these adolescents were not born at the time of the 1994 Genocide against the Tutsi, the results suggest future studies should explore the precipitating factors contributing to the PTSD symptoms within this specific group.
\end{abstract}

Keywords: PTSD, Prevalence, Survivors, In country non-targeted, Old returnees, Offspring

\footnotetext{
* Correspondence: clestino06@gmail.com

${ }^{1}$ Centre for Mental Health, University of Rwanda, Kigali, Rwanda

${ }^{2}$ Hope and Homes for Children, Salisbury, UK

Full list of author information is available at the end of the article
}

(c) The Author(s). 2019 Open Access This article is distributed under the terms of the Creative Commons Attribution 4.0 International License (http://creativecommons.org/licenses/by/4.0/), which permits unrestricted use, distribution, and reproduction in any medium, provided you give appropriate credit to the original author(s) and the source, provide a link to the Creative Commons license, and indicate if changes were made. The Creative Commons Public Domain Dedication waiver (http://creativecommons.org/publicdomain/zero/1.0/) applies to the data made available in this article, unless otherwise stated. 


\section{Background}

Post-traumatic stress disorder (PTSD), a trauma and stressor related disorder is found worldwide [1]. Estimates of the lifetime prevalence of PTSD vary considerably according to social background and country of residence, ranging from 1.3 to 12.2 [2]. In Europe, differences in PTSD prevalence range from 0.56 to $6.67 \%$ in the general population, with one outlier country, Croatia, reporting a ten-fold higher prevalence [3]. In South Africa the risk of developing PTSD after exposure to trauma and the probability of symptom chronicity after the initial onset of PTSD is highest in those who witnessed a traumatic event [4]. Post-traumatic stress disorder is present not only in adults but also in children and is associated with many factors. The prevalence of PTSD is typically elevated in populations with high rates of direct exposure to traumatic events. PTSD in children and adolescents may be caused by either direct exposure to traumatic life events or by generational transmission of trauma $[5,6]$.

Gender differences have been noted with women developing PTSD two to three times more often than men.

On a global scale, the lifetime prevalence of PTSD is about $10-12 \%$ in women and $5-6 \%$ men. When mothers are suffering from PTSD, their offspring may also be exposed. In Rwanda, considerable research has focused on the prevalence of PTSD within the general population [7]. With regard to the 1994 Genocide against the Tutsi exposure categories, there were those who were victims; currently categorized as "survivors," those who were incountry and non-targeted and those who were outside of the country; referred to as the "1959 returnees."

Less is known about differences in the prevalence of PTSD within specific groups such as women and their offspring. Our objective was to address the following questions:

1. What is the prevalence of PTSD among mothers and their offspring residing in Rwanda 25 years after the 1994 Genocide against the Tutsi? 2. Is the prevalence of PTSD associated with generational groups (mothers versus offspring)? 3. Is the prevalence of PTSD among mothers and their offspring associated with the mothers' survival category (genocide survivor, returnee, in-country nontargeted)? 4. Is the prevalence of PTSD among offspring associated with their mothers' survival status and level of exposure to trauma?) We aimed to point out the general prevalence rate from a large sample of dyads of mothers and offspring, and how the survival status in the 1994 Genocide against Tutsi can influence PTSD prevalence not only in mothers but also in offspring. It is hoped this research will open avenues for early identification of PTSD in the offspring groups and create opportunities to develop preventive interventions.

\section{Methods}

\section{Participants}

Participants were selected and placed into one of three groups based on their exposure to the 1994 Genocide against the Tutsi. The groups are representative of the different experiences of Rwandans during the genocide.

The first group was made up of 1994 Genocide against the Tutsi survivors, the second group consisted of in- country non-targeted mothers and the third group, "1959 returnees" was comprised of mothers who lived outside the country during the genocide and who later returned to Rwanda. Each group consisted of dyads of a mother and one of her offspring between the ages of 14 and 22 years old. Study participants came from seven districts: Ruhango, Gasabo, Gisagara, Huye, Rutsiro, Gatsibo,and Kamonyi. The districts were selected on the basis of having large populations of survivors and those who lived outside the country during the 1994 Genocide against the Tutsi. The population size was determined based on the G-power rule of at least 400 participants according to the type of analysis. Our sample was comprised of 432 dyads of mothers and offspring categorized by the following groups: survivors, 174 dyads, in country non-targeted, 150 dyads and returnees, 108 dyads.

Recruitment of participants was based on the following criteria: mothers were required to be Rwandese nationals and residing permanently in the country, a mother with a child of at least 14 years of age residing with her permanently since birth and who voluntarily agreed to participate in the study. Offspring met the study criteria if he or she had lived with his or her mother on a full-time basis until the minimum age of 7 years, agreed to voluntarily participate in the study and was capable of selfreporting. Participants with communication difficulties, who had experienced a mental health crisis at the time of the study, or who had a recent experience of a traumatic event or serious physical illness were excluded. Data were analysed using the Statistical Package for the Social Sciences: (SPSS version 25).

\section{Socio-demographic characteristics}

The study interviewed 432 pairs of mothers and their offspring including 174 survivors, 150 in-country nontargeted, and 108 returnees. The mothers' mean age was $48.5(\mathrm{SD}=8.01)$ while the minimum and maximum age was 32 and 87 years respectively. The majority of mothers $(64.12 \%)$ were married at the time of the interview while $22.69 \%$ were widows. Of the 432 mothers, $82.64 \%(n=357)$ reported having completed primary school, $12.96 \%(n=56)$ had completed secondary education, and only $0.93 \%(n=4)$ had completed university. The Southern Province had the highest representation in the sample with $54.17 \%(n=234)$ of participants followed by the Eastern Province with $28.01 \%(n=121)$ of the sample. The mean age for the 
offspring participants, was $17.38(\mathrm{SD}=2.02)$ and the minimum and maximum ages were 14 and 22 years respectively. All offspring lived in their respective households their entire lives. Of the 432 offspring participants, 60.88\% $(n=263)$ were female and $39.12 \%(n=169)$ were male. Furthermore, $65.74 \%(n=284)$ of offspring participants had completed secondary school, while $34 \%(n=147)$ had completed primary school education. For further details please consult Tables 2 and 3 in Appendix.

\section{Measures}

\section{The life events checklist (LEC-5)}

The Life Events Checklist (LEC-5) was used to explore traumatic events experienced by the mothers. LEC-5 is a self-report measure designed to screen for potentially traumatic events in a respondent's lifetime.

The LEC-5 assesses exposure to 16 events known to potentially result in PTSD or distress and includes one additional item assessing any other extraordinarily stressful event not captured in the first 16 items [8].

\section{The post-traumatic checklist PCL-5)}

The PCL-5 is a 20-item self-report measure that assesses the 20 DSM-5 symptoms of PTSD. The PCL- 5 has a variety of purposes, including: monitoring symptom change during and after treatment, screening individuals for PTSD, and making a provisional PTSD diagnosis. A PCL-5 cut- off point of 33 appears to be a reasonable value to propose until further psychometric work is available [8].

\section{The University of California los Angeles Posttraumatic stress disorder reaction index (UCLA-PTSD-RI)}

The University of California at Los Angeles' Posttraumatic Stress Disorder Reaction Index (UCLA-RI) has been used to measure trauma and traumatic events in offspring [9].

The new DSM-5 version is a semi-structured interview that assesses a child's trauma history and the full range of DSM-5 PTSD diagnostic criteria among school-age children and adolescents. UCLA-RI has adequate reliability and validity. A cut-off of 38 has a sensitivity of 0.93 and specificity of 0.87 in detecting PTSD.

\section{Results}

Results revealed $30.2 \%$ of our sample met the criteria for significant post-traumatic stress disorder. The prevalence of PTSD by generation is presented in Table 1. The odds of experiencing PTSD were $75 \%$ lower for offspring than their mothers ( $\mathrm{OR}=0.25, p<.001)$; while the likelihood of having PTSD in the sample was associated with the mothers' survival category (survivors, in country non-targeted, and 1959 returnees). Also, the study found that the odds of having PTSD were $75 \%$ lower for the in-country non-targeted group than the survivors' group $(\mathrm{OR}=0.25, p<.001)$, and $70 \%$ lower for the returnee group than survivors $(0 \mathrm{R}=0.30, p<.001)$.
The likelihood of offspring experiencing PTSD was associated with their mothers' survival status.

The odds of experiencing PTSD were $66 \%$ lower for offspring born from in- country non-targeted mothers than offspring of survivors (OR $=0.44, p<.001)$ and, $73 \%$ lower for offspring born from 1959 returnee mothers than offspring survivors $(\mathrm{OR}=0.27, p<.001)$. The data indicate that the mother's status; survivor, returnee or in country non-targeted, influenced their offspring's development of PTSD, whereas the level or degree of trauma experienced by the mother; high, moderate or low, did not significantly impact the development of PTSD in their offspring.

\section{Discussion}

The results demonstrated that $30 \%$ of our sample met the cut-off for probable PTSD. Mothers were four times more likely to present with PTSD symptoms than their offspring.

Given the horrors of the genocide, it was not remarkable to find mothers who had been exposed to traumatic events and exhibited significant PTSD symptoms. Exposure to multiple traumatic events in adults is associated with high levels of posttraumatic stress disorder, anxiety, and depression [10]. People exposed to multiple traumatic stressors are more likely to develop PTSD and related psychiatric symptoms than people who experience a single exposure to a traumatic event [11]. PTSD affects not only direct victims of trauma, but also their families, observers, as well as direct and indirect participants in traumatic events [12].

Survivor mothers, exhibited greater severity of PTSD symptoms followed by the returnees mothers and lastly, by in country non-targeted mothers. Results of this study demonstrated the likelihood of having PTSD in all sample groups was conditional on the mothers' survival category (survivors, in country non-targeted, and returnees) with survivors and their offspring being four times more likely to have symptoms than the in-country non-targeted group and three times that of returnee group. PTSD affects not only direct victims of trauma, but also their families, observers, as well as direct and indirect participants in traumatic events.

Studies consistently show that individuals exposed to human-generated traumatic events carry a higher risk of developing Posttraumatic Stress Disorder (PTSD) than those exposed to other kinds of events such as environmental or natural disasters.

The literature reports perceptions of social support before and after a traumatic event as an important factor in determining vulnerability in the development of PTSD [13].The Genocide against the Tutsi was a human-generated traumatic event with catastrophic and far-reaching effects on the entire society. Within 3 months, more than one million Tutsi were killed. The genocide caused far-reaching physical and psychological consequences as a result of the horrific, macabre acts of the killers. Hundreds of thousands of survivors 


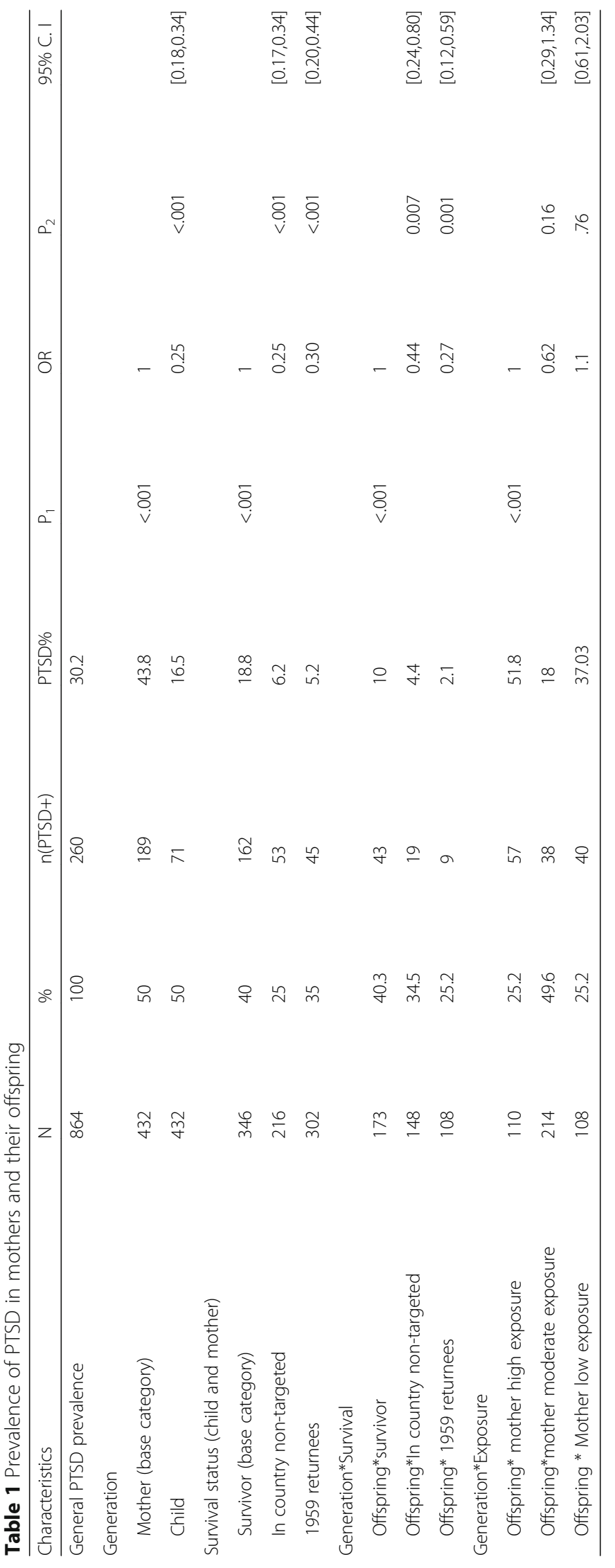


were wounded or permanently physically disabled; widowed, contracted HIV/AIDS, or were forced to live without shelter.

The very fiber of Rwandan society and sense of social cohesion were decimated. The genocide destroyed the mutual trust and sense of unity Rwandans had developed and relied upon for centuries; People separated from one another based on politically reinforced fear, hatred and mistrust [14].

Although most Rwandese have been exposed to traumatic events in their lifetime, the symptoms of PTSD were exacerbated in genocide survivors as a result of their lived experience and chronic exposure to multiple traumas during the genocide.

A curious exception was the returnee group who were not physically present in the country during the genocide, but who experienced the second highest rate of PTSD prevalence.

This indicates that the returnee group was indirectly targeted and affected by the loss of many family members.

Clinical observation and empirical research have shown that the consequences of traumatic events are not limited to the persons immediately exposed to the event, and often significant others in their environment such as children, family members, friends, and caregivers are affected. Children often feel the greatest impact of a parent's PTSD because of the parent's lack of ability to function effectively as a parent, due to their PTSD symptoms [15]. Changes in parental functioning can lead to unmet family needs and increased levels of stress for the family, specifically for the children $[16,17]$.

Our study demonstrated the likelihood of children having PTSD was conditional upon their mothers' survival status with offspring born from survivor parents twice as likely to manifest PTSD symptoms as offspring of in-country non-targeted mothers and at least four times that of offspring of the returnees.

Parents suffering from PTSD may have observable difficulties in their relationships with their spouse and children. Withdrawal, isolation, inability to express emotions, overprotection and over-control of their children are challenges they encounter while trying to function within the family system. In such family environments, important developmental stages are potentially disrupted; such as bonding, attachment and individuation, due to the fact that the parent's struggle with mental health issues places the child in an atmosphere charged with high levels of anxiety, depression and impulsivity. Parental engagement in violence against children and neglect may expose children to increased trauma. The more victims of a traumatic event manifest symptoms of PTSD, the more likely their children are also at risk of suffering from PTSD [11]. It is worth noting that the returnee mothers had the second highest level of PTSD symptoms while their offspring had fewer symptoms and the difference between symptoms of offspring born from survivor mothers and in country, non-targeted mothers was insignificant.
Further studies are needed to explore protective factors for children born from returnee mothers and to determine risk factors for the other two groups.

Our data indicate the probability of offspring having PTSD was not a condition of their mother's trauma exposure. The literature reports when the traumatic experiences of parents are not addressed, their emotional and behavioral legacy is often passed down to their children. Interestingly, this was not the case for our sample. We found no significant relationship between the mother's level of trauma and their offspring's development of PTSD.

\section{Conclusion}

Results of this study are consistent with the findings of previous research on the prevalence of PTSD symptomatology in the Rwandan population [13].

The current study provides an important addition to the literature as it explores PTSD among three groups of mothers categorized by their levels of exposure to the 1994 genocide against Tutsi.

A very high prevalence rate of PTSD was found among survivor mothers, followed by returnee mothers and lastly, by in country non-targeted mothers. These results serve to further strengthen current national efforts to heal PTSD, focusing on the genocide survivors. Overall, the results reveal a high prevalence of PTSD in Rwandese, and the most vulnerable group is the survivors and their offspring. Efforts to delineate the psychosocial, genetic or narrative factors contributing to PTSD in Rwandan offspring will be very important in further research studies.

\section{Limitations}

Parent participants in this study were restricted to biological mothers of their offspring as they are characteristically the child's principal attachment figure [4]. Further studies are needed to explore the impact of both parents on the development of PTSD in offspring as they can become attached to adults other than the primary caretaker who are sensitive and responsive in social interpersonal interactions [5].

Differences of prevalence of PTSD among the three groups of offspring were identified but further research is needed to explore possible factors contributing to the development of PTSD in offspring of mothers in the three identified groups.

Prevalence of PTSD in the mother-offspring dyads across the three groups was explored in eight out of thirty districts in Rwanda. A larger study covering the entire country would be necessary to verify the generalizability of the present study findings on the entire Rwandan population. As present districts were selected based on the criteria of having large populations of survivors and those who lived outside the country during the 1994 Genocide against the Tutsi, it would interesting to find out what results would occur from a random selection of districts. 


\section{Appendix}

Table $\mathbf{2}$ Characteristics of mother participants

\begin{tabular}{llll}
\hline Characteristics & & $\mathrm{n}$ & Percentage \\
\hline Survival status & Survivors & 174 & 40.28 \\
& In country non targeted & 150 & 34.72 \\
Age group & 1959 returnees & 108 & 25.00 \\
& $32-42$ & 71 & 16.44 \\
& $43-54$ & 201 & 46.53 \\
Marital status & $55-64$ & 148 & 34.26 \\
& 65+ & 12 & 2.78 \\
& Married & 277 & 64.12 \\
& Divorced & 49 & 11.34 \\
Education & Separated & 8 & 1.85 \\
& Widow & 98 & 22.69 \\
& Primary & 357 & 82.64 \\
& Secondary & 56 & 12.96 \\
& TVET & 13 & 3.01 \\
& University & 4 & 0.93 \\
& Adult literacy & 2 & 0.46 \\
& Kigali & 41 & 9.49 \\
& South & 234 & 54.17 \\
& West & 36 & 8.33 \\
& East & 121 & 28.01 \\
\hline
\end{tabular}

Table 3 Characteristics of offspring participants

\begin{tabular}{llll}
\hline Characteristics & & $\mathrm{n}$ & Percentage \\
\hline Survival status & Survivors & 174 & 40.28 \\
& In country non targeted & 150 & 34.72 \\
& 1959 returnees & 108 & 25.00 \\
Age group & $14-16$ & 156 & 36.11 \\
& $17-19$ & 202 & 46.76 \\
Sex & 20-22 & 74 & 17.13 \\
Education & Male & 169 & 39.12 \\
& Female & 263 & 60.88 \\
& Primary & 147 & 34.03 \\
Province of residence & Secondary & 284 & 65.74 \\
& TVET & 1 & 0.23 \\
& South & 40 & 9.26 \\
& West & 223 & 51.62 \\
& East & 36 & 8.33 \\
\hline
\end{tabular}

\section{Abbreviations}

DSM: Diagnostic Statistical Manual; LEC-5: Life Events questionnaire DSM-5; NISR: National Institute of Statistics; OR: Odds Ratio; PCL-5: PTSD Checklist for DSM-5; PTSD: Post Traumatic Stress Disorders; SPSS: Statistical Package for the Social Science; UCLA-PTSD-RI: University of California at Los Angeles, Posttraumatic Stress Disorders Reaction Index for DSM-5

\section{Acknowledgements}

The authors are grateful to the Rwanda Biomedical Center, University of Rwanda, College of Medicine Department of Clinical Psychology and Therapeutics' staff, Hope and Homes for Children and Foundation IBUKA for facilitating this study.

\section{Authors' contributions}

MC: is the first author, he contributed in study design, collection, analysis, and interpretation of data and writing the manuscript. VS: He is the supervisor of the study, and made substantial contributions to the conception of the work, data collection, analysis and manuscript writing. EN: analyzed and interpreted data and provided technical support regarding manuscript writing. LM: he contributed in depth data analysis, data interpretation, and reviewed the manuscript. CC: substantively revised the form and content of the study and she is the one who corrected English. CM: She contributed in data analysis and manuscript writing. YK: She contributed in designing the methodology used, data collection and manuscript review. All authors read and approved the final manuscript.

Funding

The fund used in this research come from the authors' budget.

\section{Availability of data and materials}

The data sets used and/or analyzed for this study are available from the corresponding author upon reasonable request.

\section{Ethics approval and consent to participate}

The study was approved by the University of Rwanda's College of Medicine and Health Sciences Ethics Committee. The objectives of the study and informed consent were explained to participants and they were assured they could withdraw from the study at any time without any repercussions. All identifying information for participants has been disguised.

To disguise the name of the participants, we used codes during data collection

Study participants voluntarily participated in the study and no monetary or other incentives were provided. Informed consent for participation had been obtained from all participants, and the consent form was written. For the minors under the age of 16; parents or legal guardians of these participants provided consent on their behalf.

\section{Consent for publication}

Not applicable.

\section{Competing interests}

The authors declare that they have no competing interests.

\section{Author details}

${ }^{1}$ Centre for Mental Health, University of Rwanda, Kigali, Rwanda. ${ }^{2}$ Hope and Homes for Children, Salisbury, UK. ${ }^{3}$ Department of Clinical Psychology, University of Kibungo, Kibungo, Rwanda. ${ }^{4}$ Medical Research Centre, Rwanda Biomedical Centre, Ministry of Health, Kigali, Rwanda. ${ }^{5}$ Mental Health Division, Rwanda Biomedical Centre, Ministry of Health, Kigali, Rwanda.

Received: 18 February 2019 Accepted: 4 December 2019

Published online: 19 December 2019

\section{References}

1. American Psychiatric Association. Diagnostic and statistical manual of mental disorders (5th Ed.). Arlington, VA: Author; 2013.

2. Karam EG, Friedman MJ, Hill ED, et al. Cumulative traumas and risk thresh olds: 12-month PTSD in the World Mental Health (WMH) surveys. Depress Anxiety. 2014;31:130 
3. Wittchen HU, Jacobi F, Rehm J, Gustavsson A, Svensson M, Jönsson B. The sizeand burden of mental disorders and other disorders of the brain in Europe 2010. Eur Neuropsychopharmacol. 2011;21:655-79.

4. Atwoli L, Stein DJ, Williams DR, Mclaughlin KA, Petukhova M, Kessler R, Koenen KC. Trauma and posttraumatic stress disorder in South Africa: analysis from the South African Stress and Health Study. BMC Psychiat. 2013. https://doi.org/10.1186/1471-244X-13-182.

5. Dekel $\mathrm{R}$, Goldblatt $\mathrm{H}$. Is there intergenerational transmission of trauma? The Case of Combat Veterans' Children. Am J Orthopsychiat. 2008;78:3.

6. Kellermann NPF. Transmitted holocaust trauma: curse or legacy? The aggravating and mitigating factors of holocaust transmission. Israel J Psychiat Related Sci. 2008;45(4):263-70.

7. Munyandamutsa N, Nkubamugisha MP, Gex-Fabry M, Eytan A. Mental and physical health in Rwanda 14 years after the genocide. Soc Psychiat Psychiatr Epidemiol. 2012;47(11):1753-6. https://doi.org/10.1007/s00127-012-0494-9.

8. Weathers, F W. Blake DD. Schnurr PP. Kaloupek DG. Marx B P. Keane, TM. The Life Events Checklist for DSM-5 (LEC-5) - Standard. (2013).

[Measurement instrument]. Available fromhttps://www.ptsd.va.gov/ professional/assessment/temeasures/life_events_checklist.asp

9. Steinberg AM, Brymer M, Decker K, Pynoos RS. The University of California at Los Angeles Post-Traumatic Stress Disorder Reaction Index. Curr Psychiat Rep. 2004;6:96

10. Suliman S, Mkabile SG, Fincham DS, Ahmed R, Stein DJ, Seedat S. Cumulative effect of multiple trauma on symptoms of posttraumatic stress disorder, anxiety, and depression in adolescents. Compr Psychiatry. 2009;50:2.

11. Breslau N, Davis GC, Andreski P, Peterson E. Traumatic events and posttraumatic stress disorder in an urban population of young adults. Arch Gen Psychiatry. 1991;48:216.

12. Wimalawansa SJ. Causes and risk factors for posttraumatic stress disorder: the importance of right diagnosis and treatment. Asian J Med Sci. 2013;5(2): 29-40. https://doi.org/10.3126/ajms.v5i2.85.

13. Charuvastra A, Cloitre M. Social bonds and posttraumatic stress disorder. Annu Rev Psychol. 2008:59:301-28.

14. Nikuze D. The Genocide against the Tutsi in Rwanda: Origins, causes, implementation, consequences, and the post-genocide era. Int J Dev Sustain. 2014;3(5):1086-98 Available at https://isdsnet.com/ijds-v3n5-13.pdf.

15. Rosenheck R, Nathan P. Secondary traumatization in children of Vietnam veterans. Hosp Comm Psychiat. 1985;36(5):538-9. https://doi.org/10.1176/ps. 36.5.538.

16. Maršanić BV, Margetić BA, Jukić V, Matko V, Grgić V. (2014). Self-reported emotional and behavioral symptoms, parent-adolescent bonding and family functioning in clinic ally referred adolescent offspring of Croatian PTSD war veterans. Eur Child Adolesc Psychiatry. 2014;23(5):295-306. https://doi.org/ 10.1007/s00787-013-0462-2 Epub 2013 Aug 15

17. Lambert JE, Holzer J, Hasbun A. Association between parents' PTSD severity and children's psychological distress: A meta-analysis. J Trauma Stress. 2014; 27(1):9-17.

\section{Publisher's Note}

Springer Nature remains neutral with regard to jurisdictional claims in published maps and institutional affiliations.

Ready to submit your research? Choose BMC and benefit from:

- fast, convenient online submission

- thorough peer review by experienced researchers in your field

- rapid publication on acceptance

- support for research data, including large and complex data types

- gold Open Access which fosters wider collaboration and increased citations

- maximum visibility for your research: over $100 \mathrm{M}$ website views per year

At $\mathrm{BMC}$, research is always in progress.

Learn more biomedcentral.com/submissions 